\title{
Short primiparous women are at an increased risk for gestational diabetes mellitus
}

\author{
Laine, M. K.
}

2018-03

Laine , M K , Kautiainen , H , Gissler , M , Raina , M , Aahos , I , Jarvinen , K \& Eriksson , J G 2018 , ' Short primiparous women are at an increased risk for gestational diabetes mellitus ' , Public Health, vol. 156 , pp. 101-108 . https://doi.org/10.1016/j.puhe.2017.12.020

http://hdl.handle.net/10138/301256

https://doi.org/10.1016/j.puhe.2017.12.020

publishedVersion

Downloaded from Helda, University of Helsinki institutional repository.

This is an electronic reprint of the original article.

This reprint may differ from the original in pagination and typographic detail.

Please cite the original version. 


\title{
Original Research
}

\section{Short primiparous women are at an increased risk for gestational diabetes mellitus}

\author{
M.K. Laine ${ }^{a, b, *}$, H. Kautiainen ${ }^{a, c, d}$, M. Gissler $^{e, f}$, M. Raina ${ }^{b, g}$, I. Aahos $^{b}$, \\ K. Järvinen ${ }^{b}$, J.G. Eriksson ${ }^{a, d, h}$ \\ ${ }^{a}$ Department of General Practice and Primary Health Care, University of Helsinki and Helsinki University Hospital, \\ Helsinki, Finland \\ ${ }^{\mathrm{b}}$ Vantaa Health Centre, Vantaa, Finland \\ c Primary Health Care Unit, Kuopio University Hospital, Kuopio, Finland \\ ${ }^{\mathrm{d}}$ Folkhälsan Research Centre, Helsinki, Finland \\ ${ }^{\mathrm{e}}$ National Institute for Health and Welfare, Helsinki, Finland \\ ${ }^{\mathrm{f}}$ Karolinska Institute, Stockholm, Sweden \\ g Apotti, Helsinki, Finland \\ h Department of Chronic Disease Prevention, National Institute for Health and Welfare, Helsinki, Finland
}

\section{A R T I C L E I N F O}

\section{Article history:}

Received 22 September 2017

Received in revised form

5 December 2017

Accepted 20 December 2017

Available online 3 February 2018

Keywords:

Adiposity

Body mass index

Gestational diabetes mellitus

Height

Nulliparous

Stature

\begin{abstract}
A B S T R A C T
Objectives: Both short stature and adiposity are risk factors for gestational diabetes mellitus (GDM). The aim of this study was to simultaneously evaluate the importance of stature and degree of adiposity on development of GDM in primiparous women.

Study design: Longitudinal cohort study.

Methods: In the city of Vantaa, Finland, between 2009 and 2015, all together 7750 primiparous women without previously diagnosed diabetes mellitus gave birth. Of these, 5223 women were $\geq 18$ years of age with information on height, weight, and complete data from a $75 \mathrm{~g}$ 2-h oral glucose tolerance test composing the study participants of this study.

Results: A $155-\mathrm{cm}$ tall woman with a body mass index (BMI) of $25.5 \mathrm{~kg} / \mathrm{m}^{2}$ had a similar risk for GDM as a $175-\mathrm{cm}$ tall woman with a BMI of $27.1 \mathrm{~kg} / \mathrm{m}^{2}$. Women shorter than $159 \mathrm{~cm}$ had the highest prevalence of GDM, 28.7\%, whereas women with height between 164 and $167 \mathrm{~cm}$ had the lowest prevalence of GDM, 19.9\% $(P<0.001)$. Height was inversely and significantly associated with both 1 - and 2-h glucose values (both $P<0.001$ ).

Conclusions: To avoid over diagnosis of GDM, an unbiased strategy is needed to determine and diagnose GDM in women with different stature and degree of adiposity.

(C) 2017 The Royal Society for Public Health. Published by Elsevier Ltd. All rights reserved.
\end{abstract}

\footnotetext{
* Corresponding author. General Practice and Primary Health Care, University of Helsinki, PO 20, 00014 Helsinki, Finland. Fax: +358 919127536.

E-mail address: merja.k.laine@helsinki.fi (M.K. Laine). 


\section{Introduction}

Gestational diabetes mellitus (GDM) is a common pregnancy complication defined as glucose intolerance with onset or first recognition during pregnancy. ${ }^{1,2}$ Today, the prevalence of GDM is estimated to be about 6\% in Europe and 9\% in North America. ${ }^{3}$ GDM is associated with adverse short- and long-term health outcomes for both women and their offspring. ${ }^{4-6}$ Usually, the diagnosis of GDM is based upon an oral 2- or 3-h glucose tolerance test with 75 - or 100 -g glucose load. ${ }^{1,7,8}$

It has previously been reported that women with GDM are at higher childbearing age, more obese, and have a shorter stature than women without GDM. ${ }^{1,4,9-16}$ Studies focusing on the influence of maternal height on fasting and postprandial glucose levels in pregnant women in relation to the risk of GDM are limited. Among Brazilian and Korean women, short stature has been shown to be associated with elevated postprandial glucose levels but not with fasting glucose concentrations. ${ }^{10,12}$ With regard to obesity, it is important to keep in mind that within different ethnic populations, a body mass index (BMI) may not correspond to the same degree of adiposity due, in part, to different body composition and thus different definition criteria for obesity have been suggested; e.g., for European populations BMI $\geq 30 \mathrm{~kg} / \mathrm{m}^{2}$ and for Asian populations $\mathrm{BMI} \geq 27.5 \mathrm{~kg} / \mathrm{m}^{2} \cdot{ }^{17,18}$

In the year 2016, we initiated a long-term follow-up study in the city of Vantaa, Finland, to evaluate the long-term consequences of gestational glucose intolerance on women's and their offspring's health. The aim of this study was to evaluate in primiparous women the association between height, degree of adiposity, and the development of GDM based on a standard $75 \mathrm{~g}$ 2-h oral glucose tolerance test (2-h OGTT).

\section{Methods}

This study is a longitudinal cohort study in the city of Vantaa, the fourth largest city in Finland. Between January 1, 2009, and December 31, 2015, in total, 7750 women without previously diagnosed diabetes mellitus delivered their first child. Of these primiparous women, 5223 women aged 18 years or more had height and weight data and complete data from a $75 \mathrm{~g} 2$-h OGTT and formed the study cohort. According to the Finnish Current Care Guidelines for GDM, GDM should be screened using 2-h OGTT in all pregnant women, except those who are at low risk, e.g. primiparous women with BMI $18.5-24.9 \mathrm{~kg} / \mathrm{m}^{2}$ without first-degree family history of diabetes. ${ }^{19}$

Data on deliveries were obtained from the Finnish Medical Birth Register, kept by the National Institute for Health and Welfare, Finland, which collects the information from the delivery hospitals. The quality of the Finnish Medical Birth Register has been found to be good. ${ }^{20}$ The following information was obtained from this register: participants' pregestational height, weight, previous pregnancies (miscarriages, induced abortions, or ectopic pregnancies) and deliveries, infertility treatment, GDM, and smoking during pregnancy. ${ }^{21}$ BMI was calculated as body weight $(\mathrm{kg})$ divided by height ${ }^{2}\left(\mathrm{~m}^{2}\right)\left(\mathrm{kg} / \mathrm{m}^{2}\right)$.

Educational attainment was defined according to the number of years of schooling and obtained from Statistics Finland. ${ }^{22}$

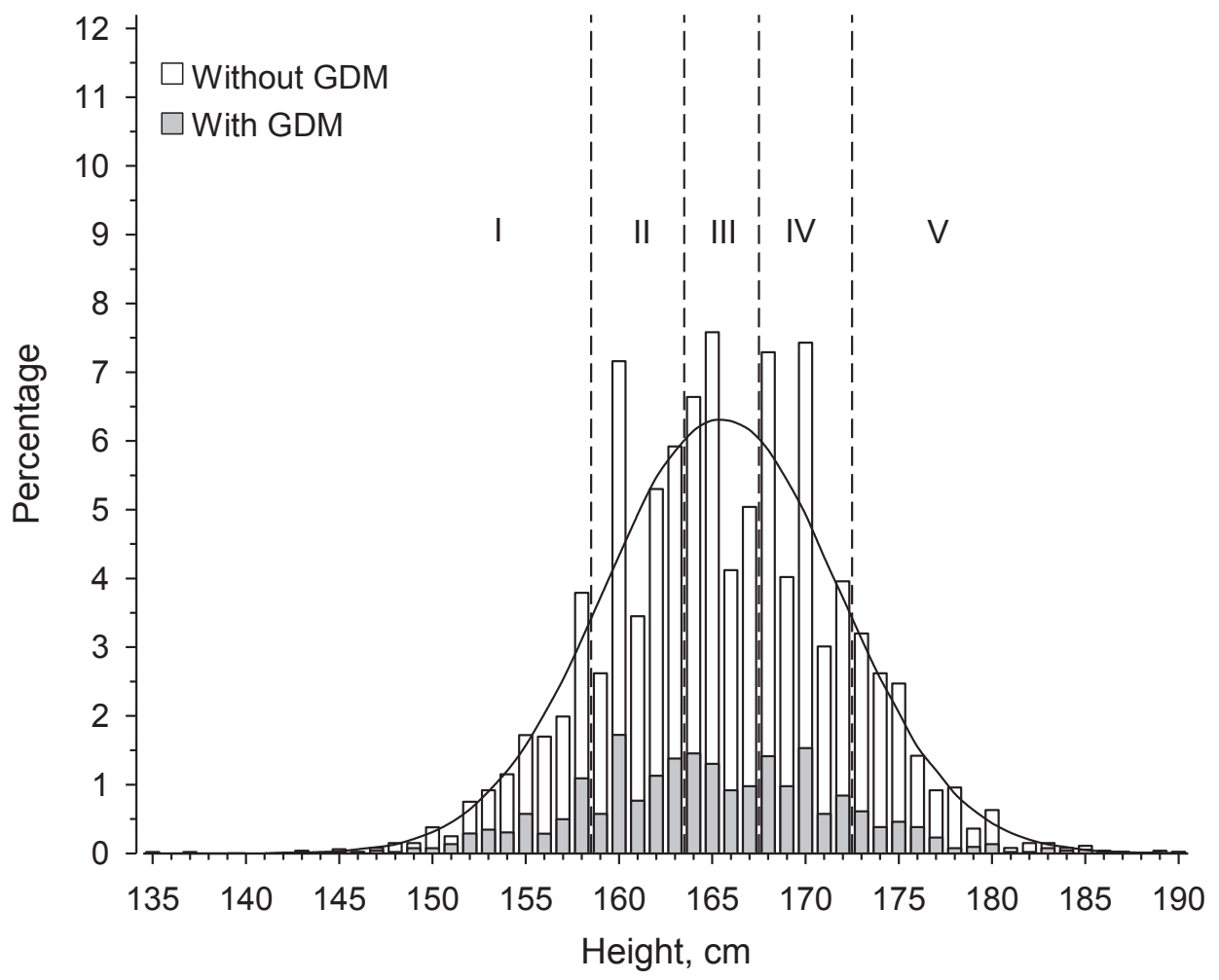

Fig. 1 - Distribution of height and percentage of primiparous women with and without GDM according to height. Cutoffs were: I $<159 \mathrm{~cm}$, II $=159-163 \mathrm{~cm}$, III $=164-167 \mathrm{~cm}$, IV $=168-172 \mathrm{~cm}$, and V > $172 \mathrm{~cm}$. GDM = gestational diabetes mellitus. 
Table 1 - Characteristics of the study participants $(\mathbf{N}=5223)$ according to height categories.

\begin{tabular}{|c|c|c|c|c|c|c|}
\hline & \multicolumn{5}{|c|}{ Height category } & \multirow[t]{2}{*}{$P$-value } \\
\hline & I [N = 689] & II $[\mathrm{N}=1277]$ & III $[\mathrm{N}=1221]$ & IV [N = 1343] & $\mathrm{V}[\mathrm{N}=693]$ & \\
\hline Height (cm), mean (range) & $155(135-158)$ & $161(159-163)$ & $165(164-167)$ & $170(168-172)$ & $176(173-190)$ & \\
\hline Age (years), mean (SD) & $28.9(4.9)$ & $29 \cdot 2(4 \cdot 8)$ & $29 \cdot 4(4 \cdot 8)$ & $29 \cdot 5(4 \cdot 8)$ & $29 \cdot 9(4 \cdot 7)$ & $<0.001$ \\
\hline Cohabiting, n (\%) & $565(82)$ & 1049 (82) & $1004(82)$ & $1105(82)$ & $586(85)$ & 0.28 \\
\hline Smokers, ${ }^{b} \mathrm{n}(\%)$ & $97(14)$ & $189(15)$ & $179(15)$ & $202(15)$ & $94(14)$ & 0.90 \\
\hline Weight (kg), mean (SD) & $59 \cdot 0(11 \cdot 6)$ & $63 \cdot 4(11 \cdot 3)$ & $67 \cdot 1(13 \cdot 0)$ & $71 \cdot 2(14 \cdot 3)$ & $75 \cdot 5(15 \cdot 7)$ & $<0.001$ \\
\hline BMI $\left(\mathrm{kg} / \mathrm{m}^{2}\right)$, mean (SD) & $24 \cdot 4(4 \cdot 7)$ & $24 \cdot 4(4 \cdot 3)$ & $24 \cdot 5(4 \cdot 7)$ & $24 \cdot 7(5 \cdot 0)$ & $24 \cdot 5(4 \cdot 9)$ & 0.32 \\
\hline Years of schooling, mean (SD) & $12 \cdot 9(2 \cdot 8)$ & $13 \cdot 4(2 \cdot 7)$ & $13 \cdot 6(2 \cdot 6)$ & $13 \cdot 7(2 \cdot 7)$ & $13 \cdot 9(2 \cdot 7)$ & $<0.001$ \\
\hline Previous pregnancies, $\mathrm{n}(\%)$ & $149(22)$ & $258(20)$ & $242(20)$ & $291(22)$ & $112(16)$ & 0.12 \\
\hline Infertility treatments, $\mathrm{n}(\%)$ & $48(7)$ & $112(9)$ & $118(10)$ & $149(11)$ & $74(11)$ & 0.002 \\
\hline Number of fetuses $\geq 2$ & $7(1)$ & $20(2)$ & $18(1)$ & $12(1)$ & $10(1)$ & 0.77 \\
\hline
\end{tabular}

GDM was defined as one or more pathological glucose values in a $75 \mathrm{~g}$ 2-h OGTT with the following diagnostic thresholds: fasting plasma glucose $\geq 5.3 \mathrm{mmol} / \mathrm{L}$, 1-h glucose $\geq 10.0 \mathrm{mmol} / \mathrm{L}$, and 2 -h glucose $\geq 8.6 \mathrm{mmol} / \mathrm{L} .{ }^{19}$

\section{Statistical analysis}

Data are presented as means with range or standard deviations (SD) or as counts with percentages. Standardized values were divided into five height level categories using $\mathrm{z}$ values: I $(<-1.5)$, II $(-1.5$ to $<-0.319)$, III $(-0.319$ to $<0.319)$, IV
(0.319 to $<1.15)$, and $\mathrm{V}(\geq 1.15)$ corresponding to grades containing $12.5 \%, 25 \%, 25 \%, 25 \%$, and $12.5 \%$ of the total distribution. Statistical significance for the hypothesis was evaluated by using generalized linear models (e.g. analysis of variance or regression models) with appropriate distribution and link function. In the case of violation of the assumptions (e.g. normality), a bootstrap type test was used. A possible nonlinear relationship between GDM or 2-h OGTT and the height was assessed by using 5-knot restricted cubic spline regression or quadratic models. The normality of the variables was tested by using the Shapiro-Wilk test. The time-weighted
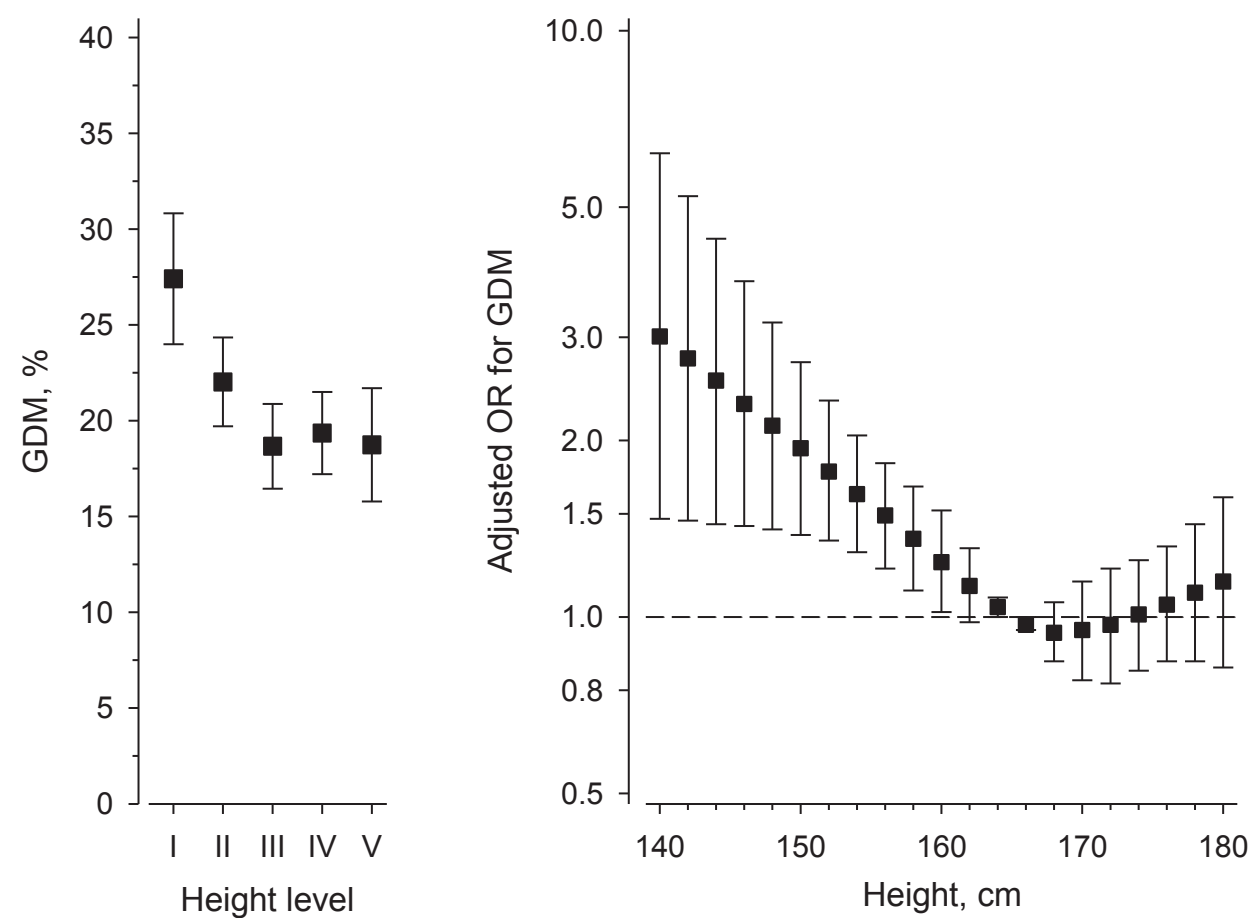

Fig. 2 - Prevalence of and estimated risk for GDM among primiparous women according to height. The left panel shows the prevalence of GDM in five height categories, adjusted for age, years of education, prepregnancy BMI, and previous pregnancies. The right panel shows the estimated risk for GDM at different height compared with $165 \mathrm{~cm}$ tall women (average height in the study cohort), adjusted for age, years of education, prepregnancy BMI, and previous pregnancies. The odds ratios were derived from a 5-knot restricted cubic splines model. Cutoffs for height categories were I $<159 \mathrm{~cm}$, $\mathrm{II}=159-163 \mathrm{~cm}, \mathrm{III}=164-167 \mathrm{~cm}, \mathrm{IV}=168-172 \mathrm{~cm}$, and V $>172 \mathrm{~cm}$. BMI = body mass index; GDM = gestational diabetes mellitus; $O R=$ odds ratio. 
area under the curve (AUC) for plasma glucose during the OGTT was determined by the trapezoidal method. Stata 14.1 (StataCorp LP; College Station, Texas, USA) statistical package was used for the analysis.

\section{Results}

Characteristics of the study participants according to height categories

A histogram showing height in the primiparous women with and without GDM is shown in Fig. 1; the mean height of the study participants was $165.5(6.3) \mathrm{cm}$. Table 1 presents characteristics of the women according to five height categories; the cutoffs were: $\mathrm{I}<159 \mathrm{~cm}, \mathrm{II}=159-163 \mathrm{~cm}, \mathrm{III}=164-167 \mathrm{~cm}$, IV $=168-172 \mathrm{~cm}$, and $\mathrm{V}>172 \mathrm{~cm}$. Height was positively associated with age, educational attainment, and infertility treatments $(P<0.001)$. In relation to the study participants' prepregnancy BMI, no statistically significant differences were observed between the height categories $(P=0.32)$.

\section{Height and GDM}

Fig. 2 shows the prevalence of GDM in different height categories, adjusted for age, years of education, prepregnancy BMI, and previous pregnancies. The women in the lowest height category $(<159 \mathrm{~cm})$ had the highest prevalence of GDM, $28.7 \%$, whereas the women in the height category $164-167 \mathrm{~cm}$ had the lowest prevalence of GDM, $19.9 \%(P<0.001)$, similar to the prevalence in the two highest height categories. Among women who were $155 \mathrm{~cm}$ tall, the odds ratio (OR) for GDM was 1.49 (95\% CI: $1.21-1.83)$ compared with $165-\mathrm{cm}$ tall women after adjustment for age, years of education, prepregnancy BMI, and previous pregnancies (Fig. 2).

Height was inversely associated with 1- and 2-h glucose concentrations (both $P<0.001)$ and glucose AUC $(P<0.001)$ during the OGTT (Table 2). Glucose AUC was inversely associated with height among women without GDM and with GDM (both $P<0.001$ ) (Fig. 3).

\section{Height, prepregnancy BMI, and GDM}

Short primiparous women with prepregnancy BMI $<25 \mathrm{~kg} / \mathrm{m}^{2}$ had a high risk for GDM (Fig. 4); 155-cm tall women had an OR

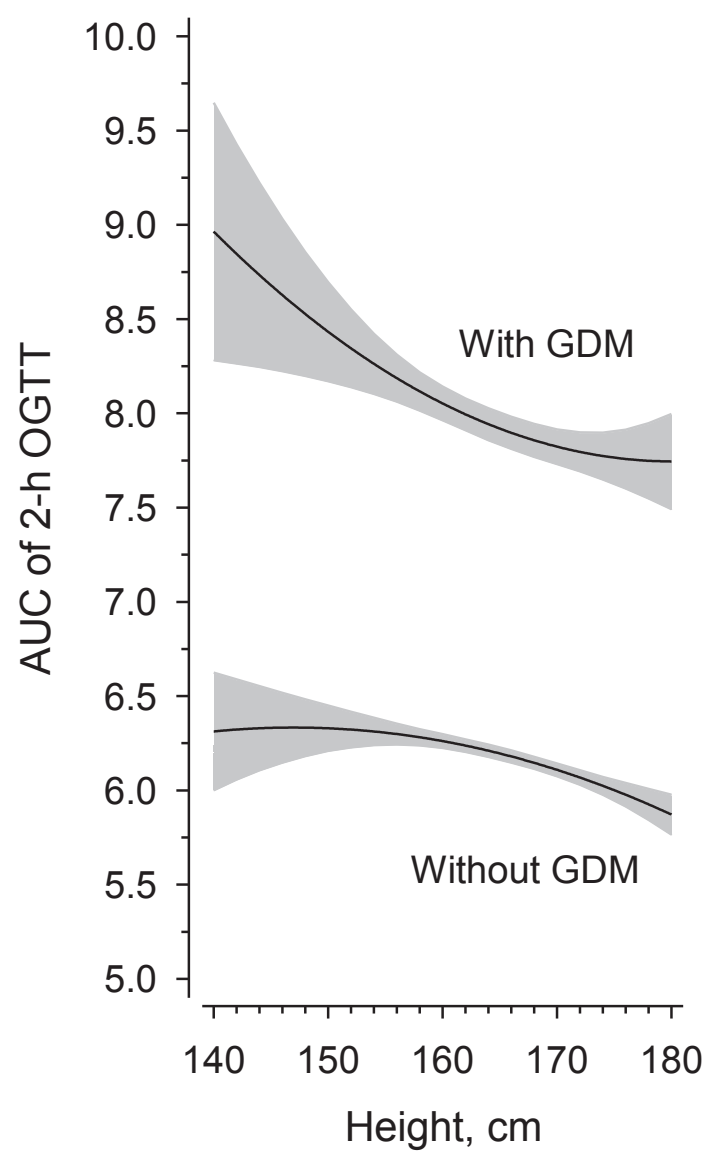

Fig. 3 - Relationship between height and AUC (2-h OGTT) in primiparous women with and without GDM (both $P<0.001)$. The models were including quadratic terms for AUC and adjusted for age, years for education, prepregnancy BMI, and previous pregnancies. AUC = timeweighted area under the curve; GDM = gestational diabetes mellitus; 2-h OGGT $=$ a 2-h 75-g oral glucose tolerance test.

of 1.54 (95\% CI: 1.16-2.04) compared with women $165 \mathrm{~cm}$ tall (adjusted for age, years of education, and previous pregnancies). Among women with prepregnancy BMI between 25.0 and $29.9 \mathrm{~kg} / \mathrm{m}^{2}, 155-\mathrm{cm}$ tall women had an OR 1.57 (95\% CI: 1.04-2.38) compared with $165-\mathrm{cm}$ tall women. The

Table 2 - Glucose concentrations during a 2-h $75 \mathrm{~g}$ OGTT and AUC in different height categories among primiparous women.

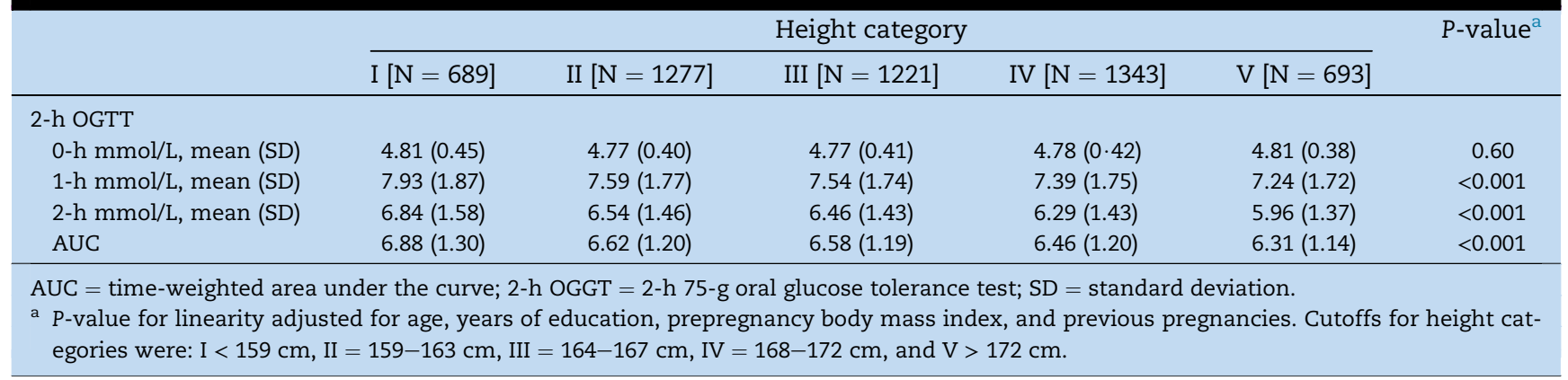



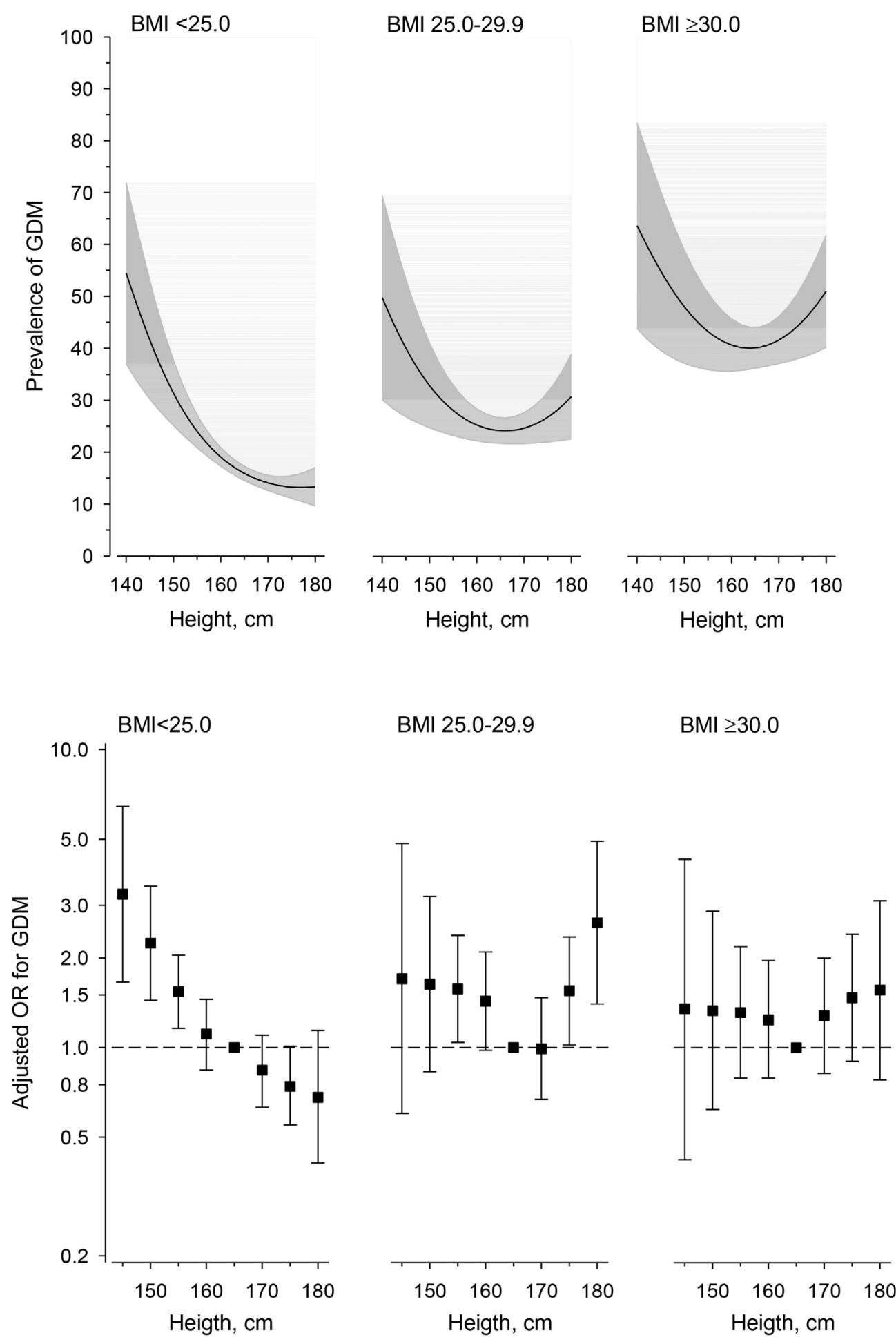

Fig. 4 - Prevalence of GDM and risk for GDM among primiparous women in different prepregnancy BMI categories according to height. The upper panel shows age-adjusted prevalence of GDM among primiparous women in different prepregnancy BMI categories by height. The lower panel shows age-adjusted odds ratios for GDM among primiparous women in different prepregnancy BMI categories according to height compared with primiparous women with $165 \mathrm{~cm}$ height (average height in the study cohort). The models were derived from a 5-knot restricted cubic splines model and adjusted for age, years for education, and previous pregnancies. BMI = body mass index; GDM = gestational diabetes mellitus; $O R=$ odds ratio. 
corresponding values for $175-\mathrm{cm}$ tall women were OR 1.55 (95\% CI: 1.02-2.35) compared with $165-\mathrm{cm}$ tall women (both adjusted for age, years of education, and previous pregnancies). Fig. 4 shows the prevalence (adjusted for age and previous pregnancies) of GDM among primiparous women in different BMI categories according to height.

GDM was diagnosed at a lower degree of adiposity in women of short stature. Fig. 5 illustrates that $155-\mathrm{cm}$ tall women and with a mean BMI of $25.5 \mathrm{~kg} / \mathrm{m}^{2}$ had a similar risk for GDM as women with BMI of $26.4 \mathrm{~kg} / \mathrm{m}^{2}$ and who were $165 \mathrm{~cm}$ tall and women with BMI of $27.1 \mathrm{~kg} / \mathrm{m}^{2}$ who were $175 \mathrm{~cm}$ (all adjusted for age).

\section{Discussion}

According to our observations, GDM was diagnosed at a lower degree of adiposity in short primiparous women compared with primiparous women of taller stature. Primiparous women in the lowest height quintile $(<159 \mathrm{~cm})$ had a prevalence of GDM of $28.7 \%$. Furthermore, short stature was associated with higher postprandial glucose concentrations but not with fasting glucose concentrations.

Also normal weight primiparous women $\left(\mathrm{BMI}<25.0 \mathrm{~kg} / \mathrm{m}^{2}\right)$ with short stature had an elevated risk for GDM, whereas in women at average or tall stature, no such association was observed. In primiparous women with BMI $25.0-29.9 \mathrm{~kg} / \mathrm{m}^{2}$, the association between height and GDM seemed to be
U-shaped. Among obese primiparous women again, height showed no association with GDM. To the best of our knowledge, this is the first study to simultaneously assess the association between height, degree of adiposity, and the development of GDM in primiparous women.

Our study findings show that primiparous women with short stature had elevated risk for GDM. This observation is consistent with the previous findings including both primiparous and multiparous women. ${ }^{9-12,14-16}$ According to our findings, primiparous women's short stature was associated with higher postprandial glucose concentrations but not with fasting glucose concentrations. These observations endorse the previous findings in primiparous and multiparous Brazilian and Korean women. ${ }^{10,12}$ On the whole, previous data on the association between height and GDM in primiparous women are very limited; most previous studies have pooled primiparous and multiparous women. $^{9-12,15,16,23}$

In the present study, primiparous women with tall stature were significantly older than women with short stature. One explanatory factor can be educational attainment; tall primiparous women had higher educational attainment. Women with low educational attainment have high incidence of GDM, which is mainly due to higher rates of adiposity. ${ }^{24,25}$

GDM is a multifactorial disease, and several factors affect the development of GDM including insulin resistance, inadequate insulin secretion from pancreatic $\beta$-cells, genetic susceptibility, and a sedentary lifestyle. ${ }^{26,27}$ Usually, insulin
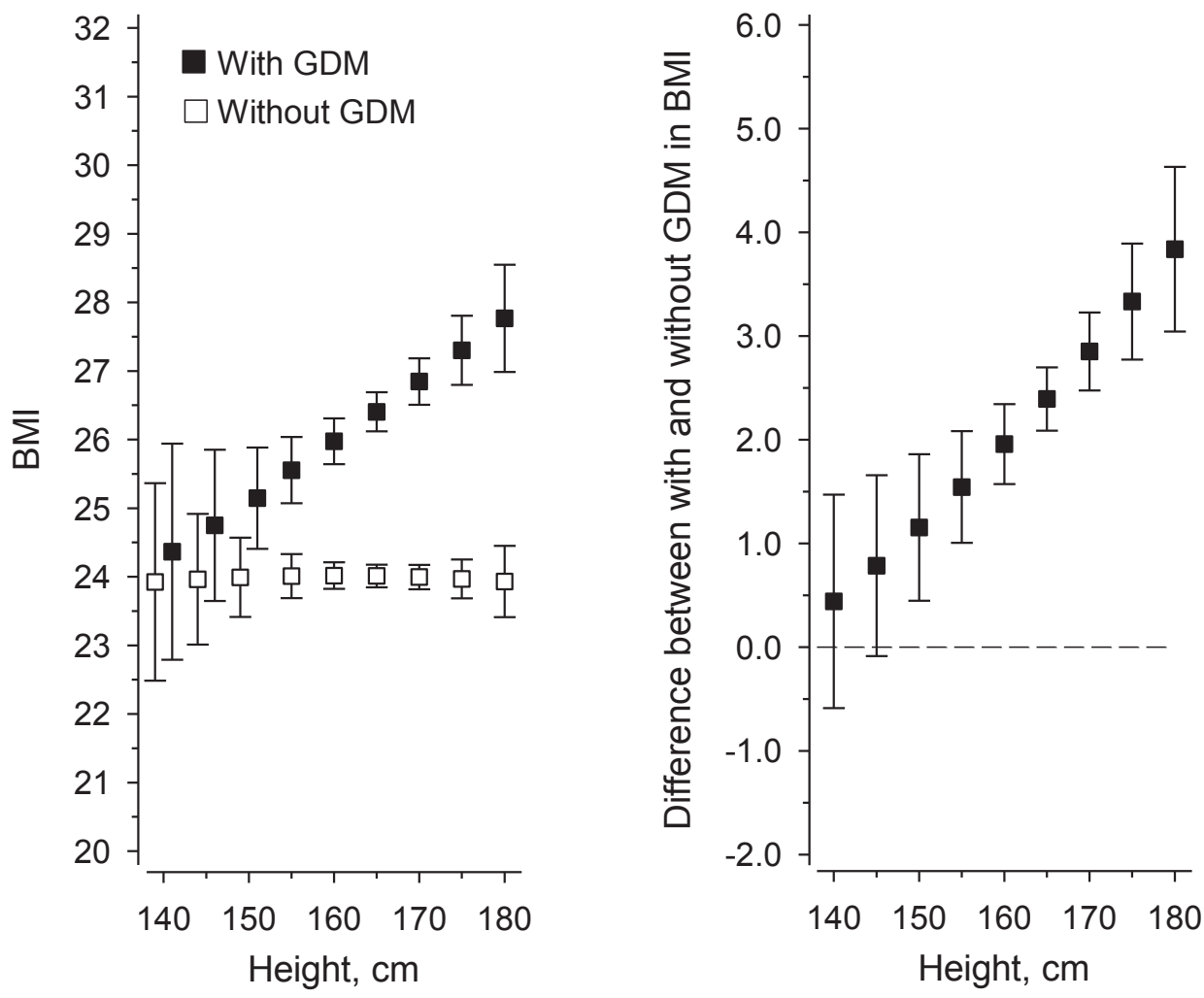

Fig. 5 - Relationship between height, prepregnancy BMI, and GDM in primiparous women. The left panel shows mean prepregnancy BMI in primiparous women at different height with or without GDM, adjusted for age. The right panel shows the differences in mean prepregnancy BMI among primiparous women at different height with or without GDM, adjusted for age. The dashed line refers to women without GDM. BMI = body mass index; GDM = gestational diabetes mellitus. 
resistance increases with the insulin-desensitizing effects of the hormonal products of the placenta and with an increase in maternal adiposity. ${ }^{26}$ Height also plays an important role. It is widely known that muscle tissue is the major tissue involved in glucose uptake and people with short stature have less muscle mass-although not necessarily a lower percentage of muscle tissue relative to total body mass-than taller people. ${ }^{28-31}$ Furthermore, a recently published study among nonpregnant people showed that height showed a positive association with $\beta$-cell function and insulin sensitivity. ${ }^{31}$ In addition, the ability to absorb and metabolize glucose in a standard OGTT seems to differ according to stature of the individual; individuals with short stature and with low fat-free mass absorb glucose slower, which is seen in a standard OGTT as high postprandial glycemic levels. ${ }^{30,32}$ Our study findings endorse these observations.

The following are the strengths of our study. Our study cohort is comprehensive; all primiparous women from the city of Vantaa, the fourth largest city in Finland, over a sevenyear time period are included. The diagnosis of GDM was based on a $75 \mathrm{~g}$ standard 2-h oral glucose tolerance test. Health care professionals measured height and it was not based on self-reports. In addition, the quality of Finnish register data is high. ${ }^{20}$

Our study has limitations. We did not have any information on family history of diabetes, body composition, gestational weight gain, physical activity, diet, or sleeping patterns. Furthermore, because almost $95 \%$ of the study population had European background and less than $4 \%$ had Asian background, the study findings cannot be generalized.

In conclusion, there seems to be a risk that women with short stature are diagnosed to have GDM because of application of a standard glucose load. Further studies are needed to find out an unbiased way to diagnose GDM in women of different stature and with different BMI.

\section{Author statements}

\section{Ethical approval}

The ethics committee of the Hospital District of Helsinki and Uusimaa and health authority of the Vantaa city have approved the study. National Institute for Health and Welfare and Statistic Finland gave permission to use their register data in this study. According to the ethics committee of the Hospital District of Helsinki and Uusimaa, and health authority of the Vantaa city, the study participants do not need to provide Informed Consents because this study is an observational register-based cohort study.

\section{Funding}

Research Foundation for Primary Health Care, Finland, and Hospital District of Helsinki and Uusimaa, Finland, awarded a research grant for this study. Samfundet Folkhälsan, Helsinki, Finland funded for the statistical analysis. The funding sources had no role for the conduct the research or preparation for the article.

\section{Competing interests}

None declared.

\section{R E F E R E N C E S}

1. Diagnostic criteria and classification of Hyperglycaemia First Detected in Pregnancy 2013. WHO. (Accessed 07/17, 2017, at $\mathrm{WHO} / \mathrm{NMH} / \mathrm{MND} / 13.2$ ).

2. American Diabetes Association. 2. Classification and diagnosis of diabetes. Diabetes Care 2017;40:S11-24.

3. Zhu Y, Zhang C. Prevalence of gestational diabetes and risk of progression to type 2 diabetes: a global perspective. Curr Diab Rep 2016;16. https://doi.org/10.1007/s11892-015-0699-x.

4. ADA. Gestational diabetes mellitus. Diabetes Care 2004;27:S88-90.

5. Bellamy L, Casas JP, Hingorani AD, Williams D. Type 2 diabetes mellitus after gestational diabetes: a systematic review and meta-analysis. Lancet 2009;373:1773-9.

6. Damm P, Houshmand-Oeregaard A, Kelstrup L, Lauenborg J, Mathiesen ER, Clausen TD. Gestational diabetes mellitus and long-term consequences for mother and offspring: a view from Denmark. Diabetologia 2016;59:1396-9.

7. ADA. Standards of medical care in Diabetes-2016: summary of revisions. Diabetes Care 2016:S4-5.

8. International Association of Diabetes and Pregnancy Study Groups Consensus Panel, Metzger BE, Gabbe SG, Persson B, Buchanan TA, Catalano PA, et al. International association of diabetes and pregnancy study groups recommendations on the diagnosis and classification of hyperglycemia in pregnancy. Diabetes Care 2010;33:676-82.

9. Anastasiou E, Alevizaki M, Grigorakis SJ, Philippou G, Kyprianou M, Souvatzoglou A. Decreased stature in gestational diabetes mellitus. Diabetologia 1998;41:997-1001.

10. Jang HC, Min HK, Lee HK, Cho NH, Metzger BE. Short stature in Korean women: a contribution to the multifactorial predisposition to gestational diabetes mellitus. Diabetologia 1998;41:778-83.

11. Kousta E, Lawrence NJ, Penny A, Millauer BA, Robinson S, Johnston DG, et al. Women with a history of gestational diabetes of European and South Asian origin are shorter than women with normal glucose tolerance in pregnancy. Diabet Med 2000;17:792-7.

12. Branchtein L, Schmidt MI, Matos MC, Yamashita T, Pousada JM, Duncan BB. Short stature and gestational diabetes in Brazil. Brazilian gestational diabetes study group. Diabetologia 2000;43:848-51.

13. Moses RG, Mackay MT. Gestational diabetes: is there a relationship between leg length and glucose tolerance? Diabetes Care 2004;27:1033-5.

14. Rudra CB, Sorensen TK, Leisenring WM, Dashow E, Williams MA. Weight characteristics and height in relation to risk of gestational diabetes mellitus. Am J Epidemiol 2007;165:302-8.

15. Brite J, Shiroma EJ, Bowers K, Yeung E, Laughon SK, Grewal JG et al. Height and the risk of gestational diabetes: variations by race/ethnicity. Diabet Med 2014;31:332-40.

16. Ogonowski J, Miazgowski T. Are short women at risk for gestational diabetes mellitus? Eur J Endocrinol 2010;162:491-7.

17. WHO Expert Consultation. Appropriate body-mass index for Asian populations and its implications for policy and intervention strategies. Lancet 2004;363:157-63.

18. Ntuk UE, Gill JM, Mackay DF, Sattar N, Pell JP. Ethnic-specific obesity cutoffs for diabetes risk: cross-sectional study of 490,288 UK biobank participants. Diabetes Care 2014;37:2500-7. 
19. Gestational Diabetes, Current Care Guidelines 2013. Working group set up by the Finnish Medical Society Duodecim, the Medical Advisory Board of the Finnish Diabetes Association and the Finnish Gynecological Association. (Accessed 07/17, 2017, at www.kaypahoito.fi).

20. Gissler M, Teperi J, Hemminki E, Merilainen J. Data quality after restructuring a national medical registry. Scand J Soc Med 1995;23:75-80.

21. Medical Birth Register 2015. THL. (Accessed 07/17, 2017, at http://www.thl.fi/en/statistics/parturients).

22. Koulutusaste 2016. STAT. (Accessed 07/17, 2017, at http:// www.stat.fi/meta/luokitukset/koulutus/001-2016/kuvaus).

23. Sina M, Hoy WE, Callaway L, Wang Z. The associations of anthropometric measurements with subsequent gestational diabetes in Aboriginal women. Obes Res Clin Pract 2015;9:499-506.

24. Bouthoorn SH, Silva LM, Murray SE, Steegers EA, Jaddoe VW, Moll H, et al. Low-educated women have an increased risk of gestational diabetes mellitus: the Generation R Study. Acta Diabetol 2015;52:445-52.

25. Collier A, Abraham EC, Armstrong J, Godwin J, Monteath K, Lindsay R. Reported prevalence of gestational diabetes in Scotland: the relationship with obesity, age, socioeconomic status, smoking and macrosomia, and how many are we missing? J Diabetes Investig 2017;8:161-7.
26. Buchanan TA, Xiang AH. Gestational diabetes mellitus. J Clin Invest 2005;115:485-91.

27. Mao H, Li Q, Gao S. Meta-analysis of the relationship between common type 2 diabetes risk gene variants with gestational diabetes mellitus. PLoS One 2012;7:e45882.

28. Boer P. Estimated lean body mass as an index for normalization of body fluid volumes in humans. Am J Physiol 1984;247:F632-6.

29. Sicree RA, Zimmet PZ, Dunstan DW, Cameron AJ, Welborn TA, Shaw JE. Differences in height explain gender differences in the response to the oral glucose tolerance test - the AusDiab study. Diabet Med 2008;25:296-302.

30. Faerch K, Pacini G, Nolan JJ, Hansen T, Tura A, Vistisen D. Impact of glucose tolerance status, sex, and body size on glucose absorption patterns during OGTTs. Diabetes Care 2013;36:3691-7.

31. Vangipurapu J, Stancakova A, Jauhiainen R, Kuusisto J, Laakso M. Short adult stature predicts impaired beta-cell function, insulin resistance, glycemia, and type 2 diabetes in Finnish men. J Clin Endocrinol Metabol 2017;102:443-50.

32. Faerch $\mathrm{K}$, Borch-Johnsen $\mathrm{K}$, Vaag A, Jorgensen $\mathrm{T}$, Witte DR. Sex differences in glucose levels: a consequence of physiology or methodological convenience? The Inter99 study. Diabetologia 2010;53:858-65. 